This is the submitted (pre-peer-review) version of the paper that has been accepted for publication by Brill's Journal of Afroasiatic Languages and Linguistics

\title{
The Syntax of Arabic Vocatives
}

Hussein Al-Bataineh

Department of Linguistics, Memorial University of Newfoundland, Canada

E-mail: hhalbataineh@mun.ca

\begin{abstract}
This paper examines the syntactic structure of Arabic vocatives, focusing on Casemarking of vocatives. The assignment of accusative and nominative Case can be accounted for in the light of Hill (2017) and Larson (2014)'s proposals. Hill (2017) provides the basic structure of the vocative phrase, and Larson (2014) proposes the internal structure of DP. The combination of these proposals explains the derivation of Arabic vocatives and their Case alternation. This paper argues that indefinite vocatives are assigned accusative Case only if they are merged with an overt D - $n$, otherwise a nominative Case surfaces on the noun by default. Proper names have the same analysis since the presence of the indefinite article-n is a prerequisite for accusative Case assignment. Concerning vocatives as heads of Construct States, N-to-D movement takes place in order to assign [+def] feature to D and is assigned accusative Case once $\mathrm{D}$ raises to the light $\mathrm{d}$. Regarding vocatives in demonstrative phrases, D-to-d movement is blocked because of the intervening constituent Dem, indicating that this operation is subject to the adjacency condition. The same analysis is applicable to definite vocatives occurring with the particle ?ayyuha.
\end{abstract}

Keywords: Vocatives; Vocative particles; dP shell; Adjacency condition; Construct State

\section{Introduction}

Vocatives are "noun phrases that refer to the addressee, but are not syntactically or semantically incorporated as the arguments of a predicate; they are rather set apart prosodically from the body of the sentence that may accompany them" (Levinson, 1983:71). Concerning the function of vocatives, Daniel and Spencer (2009:626) define vocatives as forms "used for calling out and attracting or maintaining the addressee's attention." These functions, according to Zwicky (1974:787, cited in Sonnenhauser \& Hanna, 2013:13) distinguish between two types of vocatives, namely, calls and addressees; "calls are designed to catch the addressee's attention, addresses to maintain or emphasize contact between the speaker and the addressee" as illustrated in (1):

\section{Calls}

Hey lady, you dropped your piano.

Addresses

I'm afraid, sir, that my coyote is nibbling on your leg.

Calls and addresses as vocative constructions use vocative forms of nominals with optional or obligatory particles (for details, see Hill and Stavrou, 2014:43). However, vocatives as discourse elements or markers have been extensively studied within the field of Conversation Analysis to explore their pragmatic aspects and sociolinguistic functions, but "syntactic accounts are almost non-existent" (Stavrou, 2014:299). The lack of interest in the syntactic aspects of vocatives is related to their grammatical status as non-arguments, that is to say, they "can be omitted from a sentence without 
influencing its syntactic well-formedness" (Lambrecht, 1996:267). In the past few years, a number of researchers (e.g., Daniel and Spencer, 2009; Hill, 2007, 2017; Hill \& Stavrou, 2014; Moro, 2003; Slocum, 2016; Sonnenhauser and Hanna, 2013) have begun to focus on the internal structure of vocatives from a syntactic point of view.

Considering the fact that vocatives are relatively poorly studied, this paper aims to do justice to the vocatives and to add to the existing body of literature. The major concern of this study is to explain the internal syntax of vocatives in Modern Standard Arabic, more specifically, Case alternation of vocatives. The rest of the paper is organized as follows: section 2 provides a brief description of Arabic vocatives and their Case-marking. Section 3 discusses Hill (2017)'s analysis of vocatives as VocPs (vocative phrases), and how this proposal can be modified by Larson (2014)'s dP shell structure. Section 4 considers Case alternation of Arabic vocatives in the light of the previously mentioned proposals. Section 5 summarises and concludes the paper.

\section{Vocatives in Arabic}

Compared with other grammatical issues, vocative constructions have not received indepth analysis in the Arabic grammatical tradition due to their external position in sentences. I have found very little literature dealing specifically with vocatives (e.g., Alkuwaihes, 2017; Fassi Fehri, 2012; Kasher, 2013; Moutaouakil, 1989). Moutaouakil (1989) provides a comprehensive description of Arabic vocatives in which he distinguishes between three types of $l$ - munaadaa 'the addressed': $l$-munaadaa proper (vocative of hailing), l-mustayaat bih 'the one who is called to help' (vocative of entreaty) and l-manduub 'the one who is bemoaned, lamented' (vocative of lamentation) as illustrated below by Moutaouakil (1989:139-141):

2. a. yaa xaalid-u, qtarib

O Khalid-NOM approach

'Khalid, come nearer.'

(vocative of hailing)

b. yaa la-Zayd-i-n li-xaalid-i-n

$\mathrm{O}$ to-Zayd-GEN-n for-Khalid-GEN-n

'O, if only Zayd were by Khalid's side!' (vocative of entreaty)
c. waa Zaydaah $\quad[-\mathrm{h}$ is a phonesthetic element $]$
O Zayd
'O Zayd!'

(vocative of lamentation)

The three types share the same basic structure, that is, they begin with a particle followed by a vocative. However, this paper focuses on the first type (i.e., vocative of hailing) since it is the only vocative construction utilized to attract the attention of a person who is present in the discourse setting, and it is still widely used in Modern Arabic. The following discussion deals with (i) the referential properties and syntactic categories of the vocative, (ii) the insertion of particles and (iii) Case alternation of the vocative.

\subsection{Constraints on the assignment of vocatives}

According to Moutaouakil (1989:142-143), traditional grammar discusses the assignment of vocative under the heading maa laa yunaadaa 'that which it is impossible to address' which specifies two types of constraints related to the referential properties and the syntactic category. 


\section{Referential properties}

The entity addressed should be the addressee, that is, neither the speaker him/herself nor the entity spoken of can be used as vocatives. Consider the ungrammaticality of (a) and (b) as compared to (c):

3. a. *yaa Zayd-u, qad najaHt-u

O Zayd-NOM certainiy succeeded-ls

'Zayd, I have succeeded.' (as said by Zayd )

b. *yaa Zayd-u, qaabal-tu Pab-aa-h-u

O Zayd-NOM met-ls father-ACC-3s (GEN)

'Zayd I met his ( =Zayd's ) father.'

c. yaa Zayd-u, qaabal-tu Pab-aa-ka

O Zayd-NOM met-1s father-ACC-2s (GEN)

'Zayd , I met your father.'

Moreover, the entity addressed must bear the semantic feature ANIMATE, unless the sentence is interpreted metaphorically. The word kursiyy 'chair' cannot be used as an addressee below:

4. *yaa kursiyy-u, naawil-n-i 1-milH-a

O chair-NOM give-n-ls (ACC) the- salt-ACC

'O chair, give me the salt.'

\section{Syntactic category}

The vocative constituent can be one of three syntactic categories: NP, as in (3c), relative clause as in (5), or demonstrative pronoun as in (6):

5. yaa man fašila, laa tay?as

O who lost NEG despair

'You who lost, do not despair.'

6. maaðaa turiid-u, yaa haaðaa

what want $-2 \mathrm{~s}$ o that one

'What do you want, you there?'

It cannot be a personal pronoun, as is shown below:

7. *yaa جanaa/huwa/Panta, btacid

$\mathrm{O}$ 1s / 3s/ 2s, go away

'O I/ he/ you, go away.'

The ungrammaticality of using first and third person pronouns is related to the constraint against addressing the speaker or the entity spoken of (referential properties discussed above), and it is redundant to use the second person pronoun because the entity addressed can only be the Addressee.

\subsection{Particles}

A vocative constituent is generally preceded by a vocative particle. Moutaouakil (1989:143) indicates that the traditional Arabic grammarians mention eight particles: ?a, ?ay, ?ayaa, hayaa, ?aay, ?aa and waa. Only three of the eight particles have survived 
in Modern Arabic, namely yaa, $2 a y$ and $2 a$. The particle $2 a y$ combines with the demonstrative particle ha to from one vocative particle ?ayyuhaa. Vocative constituents can also be preceded by zero particle.

The insertion of each of the particles, $\varnothing$, yaa, zayyuhaa or $7 a$, is subject to a number of conditions. For example,

1- when the vocative constituent is a proper noun or a possessor in Construct State, it can be preceded by $\varnothing, y a a, ? a$, but not $2 a y y u h a a$ as is shown below:

8. $\varnothing /$ yaa/ جa /* Payyuhaa Zayd-u, naawil-n-i 1- milH-a $\mathrm{O} \quad$ Zayd-NOM give-n-ls (ACC) the-salt-ACC

'Zayd, give me the salt.'

9. $\varnothing /$ yaa / جa / * ?ayyuhaa Sadiiq-a Zayd-i-n, Taqbil

O friend-ACC Zayd-GEN-n come

'Friend of Zayd, come.'

2- when the vocative constituent is a noun preceded by a definite article, the only acceptable particle is ?ayyuhaa:

$\begin{array}{cll}\text { 10. * } \varnothing / *_{\text {yaa } / * ? \mathrm{a} / \text { Payyuhaa }} & \text { r-rajul-u, } & \text { qtarib } \\ \text { O } & \text { the-man-NOM } & \text { approach } \\ \text { 'O man, come nearer.' } & & \end{array}$

3- when the vocative constituent is not preceded by a definite article, only yaa may be used:

$\begin{array}{lll}11 . * \varnothing / * \text { ?a / *2ayyuhaa / yaa } & \text { rajul-a-n / rajul-u, } & \text { takallam } \\ \text { O } & \text { man-ACC-n/man-NOM } & \text { speak }\end{array}$

'O man, speak.'

Such conditions indicate that the choice of a specific particle is affected by the nature of the vocative constituent. Specifically, the choice is determined by the (in)definiteness of the vocative constituent. Whether the addressee is definite or not also affects Case assignment as can be seen below.

\subsection{Case-marking}

According to Moutaouakil (1989:148), the vocative constituent can be assigned either the accusative, as in (12) or the nominative Case, as in (13):

12. a. yaa rajul-a-n, Payliq 1-baab-a

O man-ACC close the-door-ACC

'Man, close the door.'

b. yaa Sadiiq-a camr-i-n, saacid Sadiiq-a-ka

$\mathrm{O}$ friend-ACC Amr-GEN-n help friend-ACC-2s (GEN)

'Friend of Amr, help your friend.'

13. a. yaa xaalid-u, Haana waqt-u d-dahaab-i

O Haalid-NOM arrived time-NOM the-departure-GEN

'Khalid, the time has come to leave.' 
b. yaa rajul-u, jlis

O man-NOM sit down

'Man, sit down.'

c. yaa haaða r- rajul-u, btaçid qaliilan

$\mathrm{O}$ that the-man-NOM move away a little

'O that man, move away a little.

$\begin{array}{cll}\text { d. Payyuhaa } & \text { n-naaim-u, } & \text { stayqiD } \\ \mathrm{O} & \text { the-sleeping one-NOM } & \text { wake up }\end{array}$

Traditional Arabic grammarians propose that the vocative constituent receives an accusative Case because it is considered as an object of an obligatorily deleted performative verb. Thus, the structure underlying (14) is (15) in which rajul-an 'manACC' is the object of the performative verb ? $a d^{c} u u$ 'call':

14. yaa rajul-a-n

O man-ACC-n

15. ad $^{\mathrm{c}}$-uu rajul-a-n

call- ls man-ACC-n

'I call a man.'

Moutaouakil (1989) illustrates that a vocative is marked as accusative if it is nakira yayr maqSuuda 'indefinite, not aimed at' (i.e., the speaker does not know the addressee) or muDaaf 'head of a Construct State phrase,' as in (12a) and (12b) respectively. It is marked as nominative if it is a proper noun, nakira maqSuиa 'indefinite, aimed at' (i.e., the speaker knows the addressee but intends to use indefiniteness), a noun preceded by a demonstrative, or a definite noun preceded by the vocative particle جayyuhaa, as in (13a-d) respectively.

However, Case alternation of vocatives seems to be affected mainly by the definiteness of the vocative, that is, the vocative is assigned the accusative Case if it is indefinite and nominative if it is definite. This generalization is problematic in twofold: firstly, in sentence (12b) the accusative addressee is a semantically definite modified noun because it is placed in the Construct State (i.e., the speaker knows the addressee as 'friend of Amr'). Sadiiq 'friend' as the head of the Construct State is definite because it is modified the genitive DP ${ }^{c} a m r-i-n$ 'Amr-GEN-n' (for similar views, see Bardeas, 2009; Borer, 1998; Mohammad, 1988; Ritter, 1991; and Siloni, 1991). Secondly, rajul 'man' in (12a) and (13b) receives both of the accusative and nominative Case although it is indefinite (i.e., the definite article $a l$ is absent in both vocatives). The simple generalization about definiteness (i.e., the semantic solution) cannot provide an adequate analysis of Case alternation in Arabic vocatives, and a syntactic analysis may provide a better understanding. The different theories related to vocatives are considered below.

\section{Syntactic Proposals}

In this section, two proposals by Hill (2017) and Larson (2014) are examined and discussed in order to explain the internal structure of Arabic vocatives and the syntactic aspects associated with it. 


\subsection{Hill (2017)}

In a number of studies, Hill (2007, 2017; Hill \& Stavrou, 2014) attempts to provide cross-linguistic generalizations about the internal structure of vocative phrases. She (2017:334) argues that "vocative nouns project beyond DP, to a VocP (vocative phrase) level that maps the basic pragmatic features involved in the derivation of nominal expressions conveying a direct address". Hill (2017) analyses the syntactic status of pan-Balkan particles bre/vre and finds that they define the inter-personal (in)formal relation between the speaker and the type of communication (command, negotiation, pleading etc.). She (2017:338) claims that these particles are "independent of the vocative Case morphology, with which they may co-occur. The main property of vocative particles is their intrinsic addressee feature." This claim can be generalised to Arabic vocatives since the particles are independent of the Case morphology. To illustrate, the choice of a particle like yaa does not depend on the following Case which can be either accusative (e.g., rajul-a-n 'man-ACC-n') or nominative (e.g., rajul-u 'man-NOM').

Moreover, Hill (2017) rejects the treatment of vocative particles like bre/vre as interjections with no relation to grammar. She insists that the distribution and constituency of particles indicate that they are computed in the derivation of the vocative phrase as can be seen in a number of tests. Due to limitation of space, only two tests are considered below.

\subsubsection{Distribution and constituency of particles}

\section{Obligatory adjacency}

The sentence (16) shows that fronted constituents la doctor cannot separate BRE from the vocative noun:

16. Bre (*la doctor) mamaie, te rog să mergi.

BRE at doctor gran'ma you beseech $S$ go.2sGEN

Intended: 'To the doctor, gran'ma, I implore you to go there.'

The Arabic particles also cannot be detached from the vocative as seen in the ungrammaticality of (18) compared to (17):
17. جax-uu-ka,
yaa Zayd-u,
zaara-hu
${ }^{\mathrm{c}} \mathrm{Amr}-\mathrm{u}-\mathrm{n}$
Brother-NOM -2s (GEN) O Zayd-NOM visited-3s (ACC) Amr-NOM-n
'Zayd, your brother, Amr visited him'

18. yaa (*2ax-uu-ka) Zayd-u, zaara-hu cAmr-un

(Moutaouakil, 1989)

The fronted constituent 2axuuka 'your brother' cannot be positioned between the particle yaa and the vocative Zayd.

Hill (2017:340) provides further evidence that interjections can occur anywhere in-between constituents but not between BRE and the vocative noun in (19):

19. (Mda) bre (*mda) Ioane, unde te duci

INT bre INT Ion where REFL go-2s (GEN)

'Hm, John, man, where do you go?'

The interjection $m d a$ is disallowed between bre and the vocative noun Ioane in (19). Also in Arabic, an interjection like ?ufin 'Damn!' cannot occur between yaa and Zayd 
in (17) above. Thus, the obligatory adjacency between the particle and the vocative indicates that they are computed together.

\section{BRE c-commands the nominal phrase in vocatives}

There is a restriction of the word order in vocative phrases. The particle always precedes the noun which indicates that the particle "selects the vocative noun phrase, which can either stay in situ, in a complement position or move to a Specifier related to the selector" (Hill:2017:340), consider (20):

20. Bre mamaie,... VERSUS *Mamaie bre,...

In Arabic, vocative particles always precede the noun, and it is impossible to have a structure like Zaydu yaa.

Further evidence for the c-command position of particles comes from coordination, as in (21): vre selects the Coordination Phrase containing the two noun phrases, since it cannot be repeated on the second constituents.

21. Vre Maria ke (*vre) Kosta....

VRE Maria and VRE Kosta...

'Maria and Kosta, ....'

To the best knowledge of the researcher, there are no studies that discuss coordination in vocatives. Based on the researcher's intuitions, the same pattern occurs in Arabic in which only one particle is used with coordinated nouns like in (22):

22. Yaa zayd-u wa xaalid-u

O Zayd-NOM and Khalid-NOM

In short, the previous argument indicates that the vocative particle like bre or yaa is syntactically computed in the derivation of the vocative phrase: "it is either the selector of the relevant nominal phrase or is in a local relation with the element that selects that nominal phrase" (Hill, 2017: 341).

\subsubsection{Functional features}

Hill (2017: 341) argues that vocative particles have two features, namely, the interpersonal [i-p] feature and the second person feature. The inter-personal feature concerns the (in)formal relation between the speaker and the addressee, and the [2nd] feature validates the interpretation of the vocative DP as the reference for the addressee.

\subsubsection{The inter-personal [i-p] feature}

According to Hill (2017:341), the presence/absence of a particle like bre affects how the interpersonal relation between the speaker and the addressee is interpreted. That is to say, the addition of the particle becomes obligatory with formal addresses and optional with informal addresses. This claim seems inconsistent with Arabic particles which are used with formal and informal addresses alike. In other words, Arabic particles cannot be categorised into two sets depending on the degree of formality between the speaker and the addressee. However, Hill (ibid) claims that the association between the [i-p] feature and a particle like bre involves syntactic rather than lexical processing, she provides three arguments related to agreement, the use of the morphological vocative Case and the placement of the definite article. 


\section{Agreement effects}

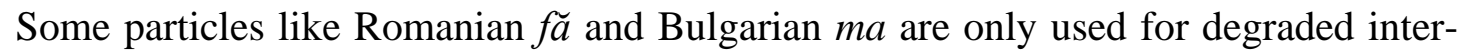
personal relation; they are only used with feminine singular nouns. "The selected noun has to conform to the grammatical gender of the particle" (Hill 2017: 342). However, this argument is incompatible with Arabic because particles do not have grammatical gender, and no agreement is required between the particle and the vocative.

\section{Vocative Case}

Not only particles like Romanian $f \tilde{a}$ and Bulgarian $m a$ above but also the vocative Case can also convey the [i-p] feature as shown below:

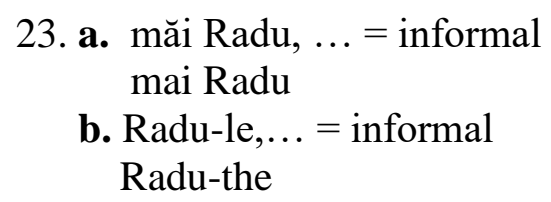

The absence of the particle măi in (b) does not affect the inter-personal relation between the speaker and the addressee to be interpreted as informal since the vocative Case conveys the [i-p] feature. Thus, Hill (ibid) claims that the [i-p] feature is a property of the vocative phrase, not only of the particle. In Arabic, Case-marking whether it is nominative or accusative does not affect the inter-personal relation between the speaker and the addressee (cf. the different marking of zayd-a-n 'Zayd-ACC-n' and zayd- $u$ 'Zayd-NOM').

\section{The definite article}

Hill argues that the definite article in vocatives is not associated with definiteness since the addressee is inherently definite. The presence of the definite article is only related to the inter-personal relation. That is to say, the definite article is present in a respectful address to an inferior party (e.g., a waiter), and it is absent in a condescending address to a minor. This argument is also incompatible in Arabic simply because the definite article $a l$ does not indicate an (ir)respectful address to an inferior or superior person.

To conclude, the three arguments for the existence of [i-p] feature can not be generalized cross-linguistically. This feature seems irrelevant in Arabic vocatives, or at least syntactically irrelevant.

\subsubsection{The [2nd] person feature}

Hill (2017: 343) states that the [2nd] feature is essential for validating the interpretation of the vocative DP as the reference for the addressee. The existence of this feature restricts the interpretation of the vocative noun to the second person. Regarding Arabic vocatives, it is stated above that the entity addressed should be the addressee, that is, neither the speaker him/herself nor the entity spoken of can be used as vocatives. Consider the ungrammaticality of sentences ( $3 a)$ and ( $3 b)$ as compared to ( $3 c)$, repeated below as (24 a-c):

$$
\begin{aligned}
& \text { 24. a. *yaa Zayd-u, qad } \quad \text { najaHt-u } \\
& \text { O Zayd-NOM certainiy succeeded-ls } \\
& \text { 'Zayd, I have succeeded.' (as said by Zayd) }
\end{aligned}
$$


b. *yaa Zayd-ui, qaabal-tu 7ab-aa-hu

O Zayd-NOM met-ls father-ACC-3s (GEN)

'Zayd, I met his (=Zayd's) father.'

c. yaa Zayd-ui, qaabal-tu Zabaa-kai

O Zayd NOM met- ls father ACC -2sG

'Zayd , I met your father.'

To sum up, I claim that the feature [i-p] is not present in Arabic while [2nd] person feature is essential for accounting for the ungrammaticality of sentences like the previous ones. However, Hill (2017:345) argues that these two features cannot be associated with the functional head $\mathrm{D}$, and a further functional projection is needed for checking them. This projection is labelled as a VocP (vocative phrase).

\section{VocP}

The structure of a vocative phrase includes a VocP which is present in any vocative phrase, cross-linguistically. Hill (ibid) proposes the following representation:

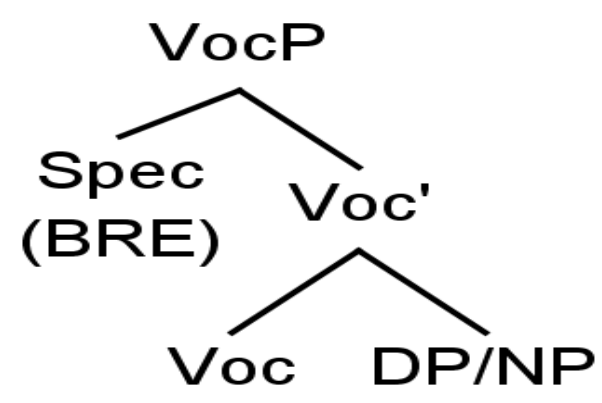

This proposal indicates that vocative phrases can be DPs or NPs cross-linguistically or language internally. In the case of NP, feature checking involves a movement of $\mathrm{N}$ to Voc, and in the case of DP, feature checking requires a movement of DP to Spec, VocP or distance Agree. In agreement with this proposal, I claim that this structure is essential for checking the [2nd] feature of a particle like yaa which restricts the selection of an appropriate vocative noun. However, this proposal does not provide us with a means to account for Case alternation (i.e., accusative vs. nominative) in Arabic vocatives. So, Hill (2017)'s representation of VocP needs to be modified by another structure not related to NP or DP, but rather dp as suggested by Larson (2014).

\subsection{Larson (2014)}

Based on the Generalized quantifier (GQ) theory (Frege, 1950), Larson (2014) emphasises the relational view of determiners that determiners express relations among predicate meanings. Under the relational view, Larson (2014:409) argues that determiners are parallel to verbs since both are semantically contentful and possess argument structure and valence. The semantic parallels between $\mathrm{V}$ and $\mathrm{D}$ can be seen in their thematic roles and thematic hierarchy. Verbs describe events, with concepts like agent, theme, goal, and so on representing the functional roles that verbal arguments play. Analogical to verbs, determiners express quantifications, with concepts like restriction and scope representing the functional roles that set arguments play in quantification. Larson (2014:410) states that

semantically, the restriction fixes the domain of quantification, whereas the scope determines what is true of the individuals in that domain. Syntactically, restriction and scope also appear relevant in mapping the parts of DP. The 
former role is mapped to the NP complement of D. The latter role is associated with a main clause predication.

The notions of scope and restriction can be seen as the counterparts of verbal thematic roles: $\theta$-RESTRICT and $\theta$-SCOPE. Some determiners have a third set argument, typically introduced by an oblique, preposition-like element such as than, as, or except, these determiners have certain oblique thematic roles for predicate arguments: NOBLIQUE ("nominal oblique"), counterpart to the oblique thematic roles found in the verbal system. The resulting comparison is as follows:

$\theta$-roles and Thematic Hierarchy for V and D:

V: $\theta$ AGENT $>\theta$ THEME $>\theta$ OBLIQUE

\section{D: $\theta$ SCOPE $>\theta$ RESTRICT $>\theta$ NOBLIQUE}

Considering the strong resemblance between $\mathrm{V}$ and $\mathrm{D}$ at the semantic-thematic level, Larson (2014:411) argues that VP and DP exhibit close structural parallelism. Pronouns (he, them, etc.) are analyzed as the counterparts of unergative verbs, taking only a scope argument (25b) as their subjects:

25. a)

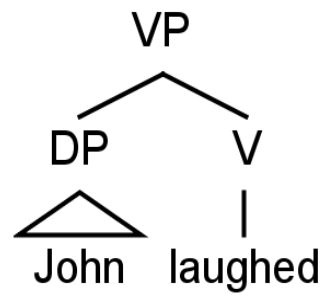

b)

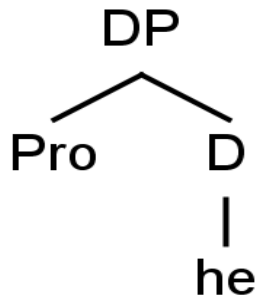

Standard binary quantifiers (all, most) are counterpart to transitive verbs, taking both a scope argument and a restriction (26b):

26. a)

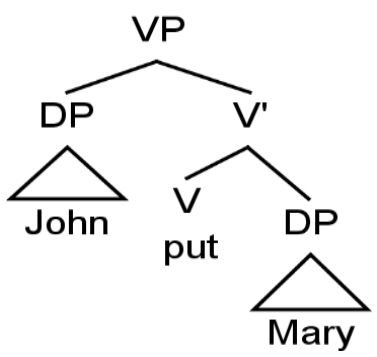

b)

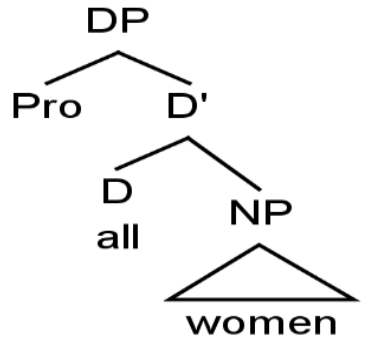

Comparatives (more) and quantifiers with exception phrases (every-except) are counterpart to ditransitive verbs, taking a scope argument, a restriction, and an oblique complement (27b): 

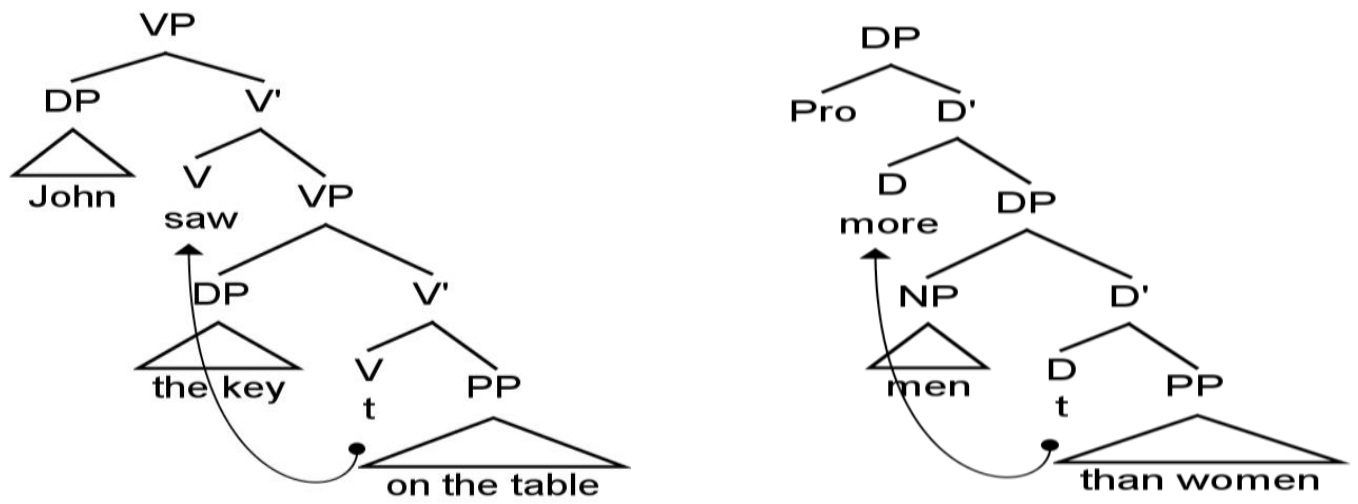

Each of these DP structures involves a null anaphoric element Pro in subject position. The existence of this external subject argument for determiners entails the existence of DP shells for ditransitive determiners equivalent to VP shells for ditransitive verbs. Concerning issues related to $\theta$-Features and $\theta$-Agreement, Larson (2014: 413) argues for the existence of a light $\mathrm{d}$, fully analogous to little $\mathrm{v}$, with the following properties:

Light d:

Bears a strong D feature. Bears an EPP feature. Bears one valued occurrence of a $\theta$-feature unvalued on a $\mathrm{D}$ with which it was co-selected.

The light $\mathrm{d}$ causes raising of D and d-D agreement, and Pro merges in order to satisfy d's EPP feature. Thus, a DP like every man has the following structure:

28.

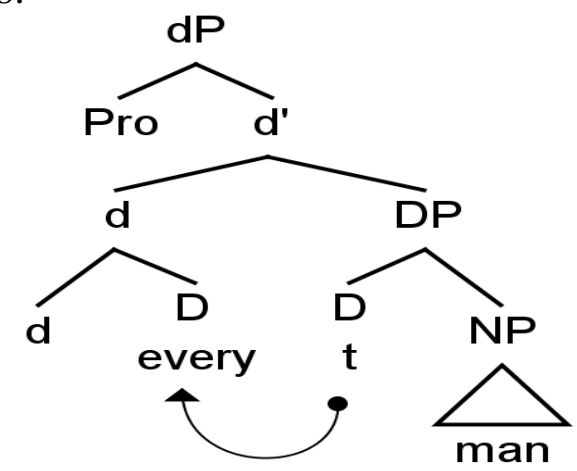

This $\mathrm{dP}$ structure is similar to the following transitive vP structure:

29.

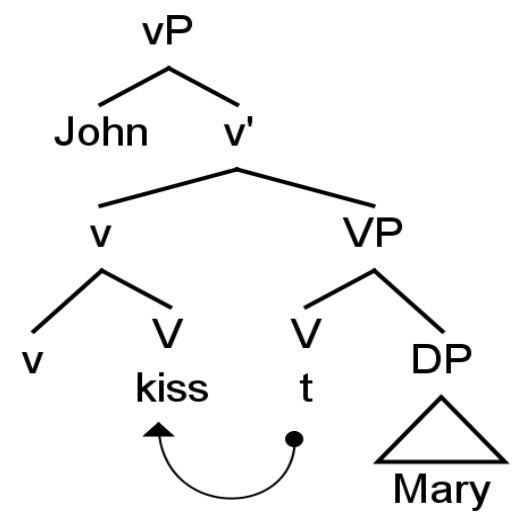


To sum up, Larson (2014) provides an interesting parallelism between DPs and VPs in a convincing and reasonable way. This parallelism covers the selection of arguments and the projection to shell structures, namely, vPs and dPs. Assuming the validity of this proposal, the analysis of $\mathrm{dP}$ structure can be extended further to cover Case assignment in which little $\mathrm{d}$ assigns Case in the same way little v does (cf. Slocum, 2016). Case assignment of little $d$ solves the problem of Case alternation (nominative vs. accusative) in Arabic vocatives and provides an adequate analysis of the phenomenon. The combination of Hill (2017)'s VocP structure and that of Larson (2014)'s dP shell yields the following structure for Arabic vocatives:

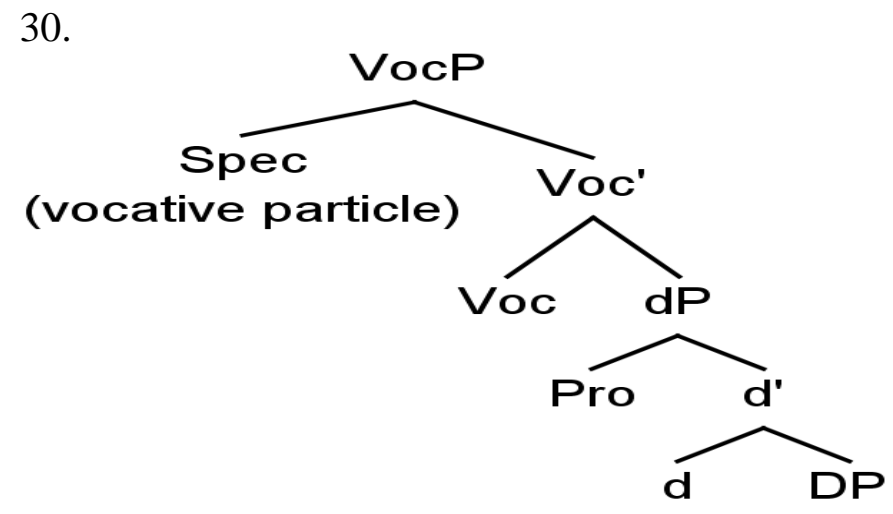

\section{Arabic vocatives revisited}

As stated in section (1), Arabic vocatives are assigned either accusative or nominative Cases. Case alternation seems syntactically rather than semantically constrained. That is to say, Case assignment is not related to semantic features like DEFINITE (as argued in the literature), rather it is related to the role of light $d$ as a Case assigner in the vocative phrase. In this section, I argue that a minimalist analysis can account for Casemarking, and the proposed structure in (30) can provide an adequate explanation for Case alternation. The following subsections deal with the different categories of vocatives, namely, indefinite nouns, proper names, nouns in the Construct State and nouns in the demonstrative phrase.

\subsection{Indefinite vocatives}

Moutaouakil (1989:148) states that the indefinite vocative constituent can be either accusative (12a) or nominative (13b), repeated as $(31 a, b)$ :

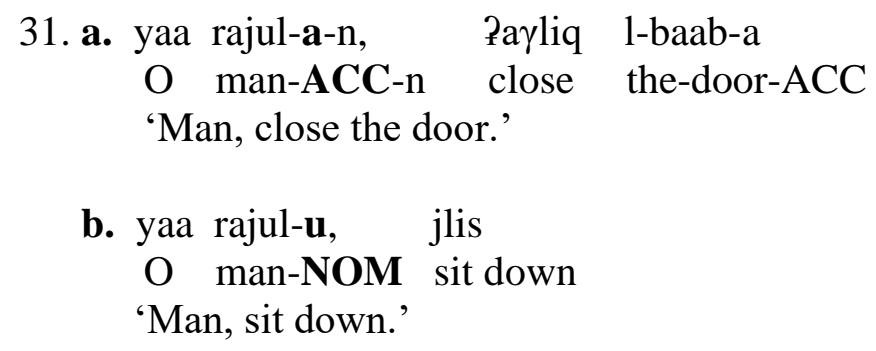

The proposed analysis of Case alternation of indefinite nouns is that the vocative is marked as accusative if it is nakira yayr maqSuuda 'indefinite, not aimed at' (i.e., the speaker does not know the addressee), and it is marked as nominative if it is nakira maqSuиa 'indefinite, aimed at' (i.e., the speaker knows the addressee but intends to use indefiniteness). Traditional grammarians focus on the intention of the speaker and his/her previous knowledge of the addressee in differentiating between the two cases. These notions of intentions and knowledge do not provide us with a means to explain Case alternations between indefinite vocatives. In other words, it is not clear why the 
'indefinite, not aimed at' is accusative rather than nominative (and vise versa). What is more interesting in Case alternation between the indefinites above is the presence of nunation $-n$ (indefinite article) in the accusative Case, and the absence of it in the nominative. It seems that the indefinite article plays a role in Case assignment in vocatives.

Fassi Fehri (2012:193) differentiates between 'pure-bare' nouns which bears no prefix and no suffix like rajul- $u$ 'man-NOM' and 'pseudo-bare' nouns which bears a suffixed [-n] like rajul-a-n 'man-ACC-n'. He (2012:223-224) indicates that pure-bare Ns are used in individuating vocatives, that is, they are utilised to refer to a unique addressee (similar to the traditional view of 'indefinite, aimed at'), and 'pseudo-bare' are used in non-individuating vocatives to refer to non-unique addressee. The different uses of bare nouns in (non)individuating vocatives make Fassi Fehri $(2012,2006)$ argue for the existence of individuating feature [+/- Indiv] in D. So, pure-bare Ns like rajul-u have the feature [+indiv], and pseudo-bare Ns like rajul-a- $n$ have the feature [-indiv]. This feature triggers $\mathrm{N}$-movement (i.e. "the movement of a noun out of the head $\mathrm{N}$ position of NP into a higher head position within the nominal expression containing it" (Radford, 2009:172)). Fassi Fehri (2012:217) argues that N moves to D in order to value the [Indiv] feature. Pure-bare Ns designating a unique addressee move to $\mathrm{D}$ which hosts [+indiv] while pseudo-bare Ns designating a non-unique addressee do not move to $\mathrm{D}$ because $\mathrm{D}$ hosts [-indiv] (the indefinite article $-\mathrm{n}$ is a marker of non-individuation [- Indiv]). Therefore, the presence of indefinite article -n blocks or prevents N-to D movement because $-n$ in rajul-a- $n$ indicates that rajul 'man' is non-individuated (i.e., [-indiv]).

However, Fassi-Fehri's analysis cannot explain why when the indefinite article - $n$ is overt the noun carries accusative Case, but when it is null the noun carries nominative Case. Admittedly, the differentiation between pure-bares and pseudo-bares is so important for explaining Case alternation, but the argument that $-n$ prevents $\mathrm{N}$-to$\mathrm{D}$ movement is counterintuitive simply because $-\mathrm{n}$ is affixal in nature and needs a host to be attached to. Following other researchers (e.g, Beina, 2014; Mohammad, 1988; Ouhalla, 1988; Rubin, 2002), I claim that movement of N-to-D crucially depends on the presence of an article in D. Bearing in mind that both the definite article $a l$ and the indefinite article $-n$ are affixal in Arabic, the existence of an overt article in D requires the movement of $\mathrm{N}$ to satisfy the need of the article to attach to an appropriate element, in this case, a nominal category (for a detailed study of Arabic determiners and N-to-D movement, see Beina (2013)). If D is null, the N-movement is not required (i.e., there is no an affix to be stranded). Assuming the validity of this claim, pure-bare Ns in a vocative phrase like yaa rajul-u 'O man-NOM' stays low in DP, and pseudo-bare in yaa rajul-a-n 'O man-ACC-n' move to $\mathrm{D}$ to attach to the affix $-\mathrm{n}$. The analysis of $\mathrm{N}$ movement provides us with the first step to account for Case alternation in bare vocatives.

Before explaining the structure of vocatives, two points need to be explained. Firstly, in the light of the parallelism between vPs and dPs discussed above, I argue that little $\mathrm{d}$ is a transitive probe which assigns accusative Case to a goal with an unvalued Case feature. This assumption is supported by the proposal of traditional Arabic grammarians that the vocative constituent receives an accusative Case because it is considered as an object of an obligatorily deleted performative verb. Thus, the structure underlying (32) is (33) in which rajul-a-n 'man-ACC-n' is the object of the performative verb $? a d^{c}-u$ ' 'call-ls': 
32. yaa rajul-a-n

O man-ACC

33. $\mathrm{Pad}^{\mathrm{c}}$-uu rajul-a-n

call-ls man-ACC-n

'I call a man.'

(Moutaouakil, 1989:148)

The argument for an underlying deleted verb is similar to that for an invisible (null) causative verb MAKE in transitive structures like He rolled the ball down the hill (meaning He made the ball roll down the hill (Radford, 2009:346)). That is to say, the deleted verb $7 a d^{c}-u u$ 'call-ls' is similar to MAKE in the sense that it is affixal in nature and triggers raising of a lexical category. Assuming the validity of this argument, little $\mathrm{d}$ in vocative phrases is a transitive probe with the capacity to assign accusative Case to $\mathrm{D}$. The second point is that the vocative noun comes into the derivation with a default Case feature. According to a number of researchers (e.g., Al-Balushi, 2011; Fassi Fehri, 1993; Mohammad, 2000; Soltan, 2007), nominative Case is the default Case in Arabic. Nominative Case is not only the default Case but also the least marked. In Woolford (2003:542-543)'s words,

Languages avoid marked Cases, using the least marked Case that can be licensed in any construction. In dative and ergative subject constructions where the object can potentially be licensed for either nominative or accusative Case, nominative is preferable as the less marked Case, but using nominative means tolerating an imperfect checking domain. Icelandic and Hindi use the less marked Case, tolerating the imperfect checking domain.

Therefore, the vocative noun comes into the derivation with a default Case feature, which may be valued as nominative in the case of imperfect checking domain, that is, if little $\mathrm{d}$ cannot assign accusative Case to the vocative noun, the latter is assigned a nominative Case by default. Bearing the previous two points in our minds, we can account for Case alternation in yaa rajl-a-n 'O man-ACC-n' and yaa rajul- $u$ 'O man-NOM'. The derivation of the first vocative phrase starts with the following structure:

34.

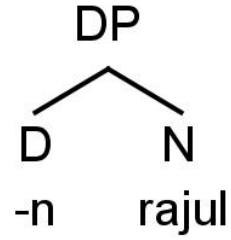

The noun rajul starts in $\mathrm{N}$ with unvalued Case feature [uCase] and merges with $\mathrm{D}$, the indefinite article - $n$, to form DP. Since - $n$ is an affix, it requires a host to be attached to, that is, the noun rajul. In this Case, either $\mathrm{D}$ lowers onto $\mathrm{N}$ by the operation of affix hopping (Radford, 2009:104), or N moves to D. Beina (2013:35-37) argues for N-to-D movement due to phonological (i.e., constraints against consonant clustering) and syntactic (i.e., the placement of adjectives after nouns) reasons. Adopting Beina (2013)'s view, I assume that the noun rajul moves to -n as in the following structure:

35. 


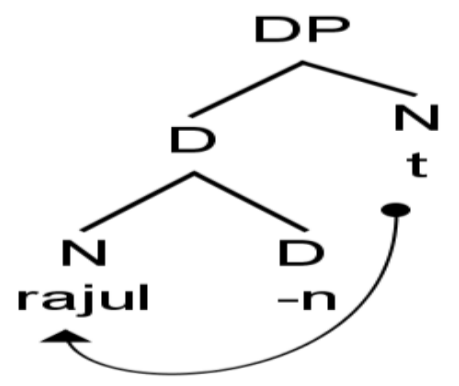

This DP is then merged with light $d$ with valued accusative feature to form d'. As stated by Larson (2014:413), light d "bears a strong D feature," so it is a strong affix (like little v) and attracts D rajul- $n$. The transitive probe light $\mathrm{d}$ assigns accusative Case to the goal D rajul- $n$ which it c-commands, consequently, rajul- $n$ becomes rajul-a- $n$. The resulting d-bar structure is then merged with pro since light $d$ bears EPP feature (Larson, ibid) to form the complex $\mathrm{dP}$. Finally, the resulting $\mathrm{dP}$ is merged with voc to form voc' which is in turn merged with the particle yaa to form VocP as in (36):

36.
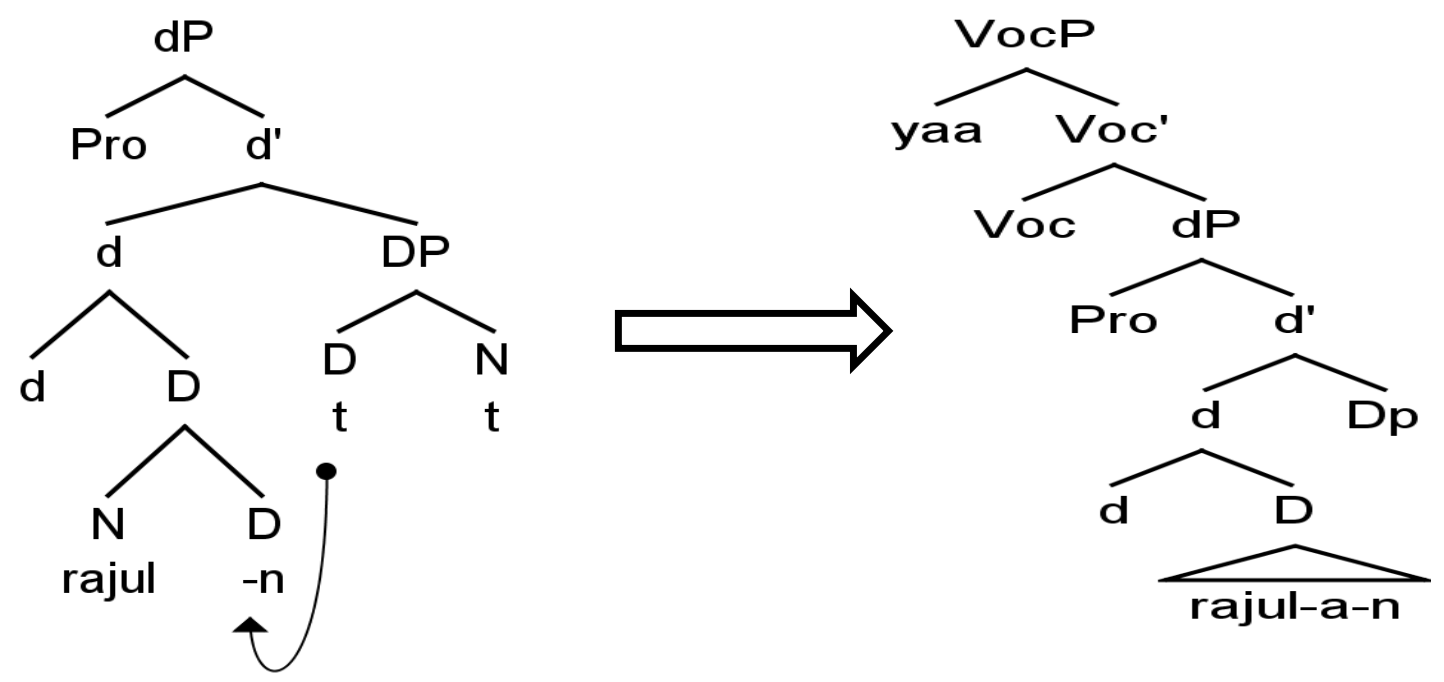

On the other hand, the nominative Case assigned to rajul in yaa rajul-u can be accounted for straightforwardly by assuming the same structure above. That is to say, the absence of an overt determiner like -n makes the noun rajul remains in situ since there is no affix that needs a host. The light $\mathrm{d}$ attracts the null $\mathrm{D}$ in the same way like in the previous structure. In this case, the light $d$ invisibly assigns accusative Case to the null $\mathrm{D}$, in other words, the null $\mathrm{D}$ absorbs the Case assigning properties of the head $\mathrm{d}$ (in the same way that a clitic absorbs Case in clitic doubling constructions in Semitic languages, for details see, Borer, 1984; Ritter, 1991; Siloni, 1991), and no valued Case features are available for the noun rajul. Therefore, rajul is assigned the nominative Case since it is the least marked, default Case. In Woolford (2003:542-543)'s words, "using nominative means tolerating an imperfect checking domain." Consider (37): 
37.

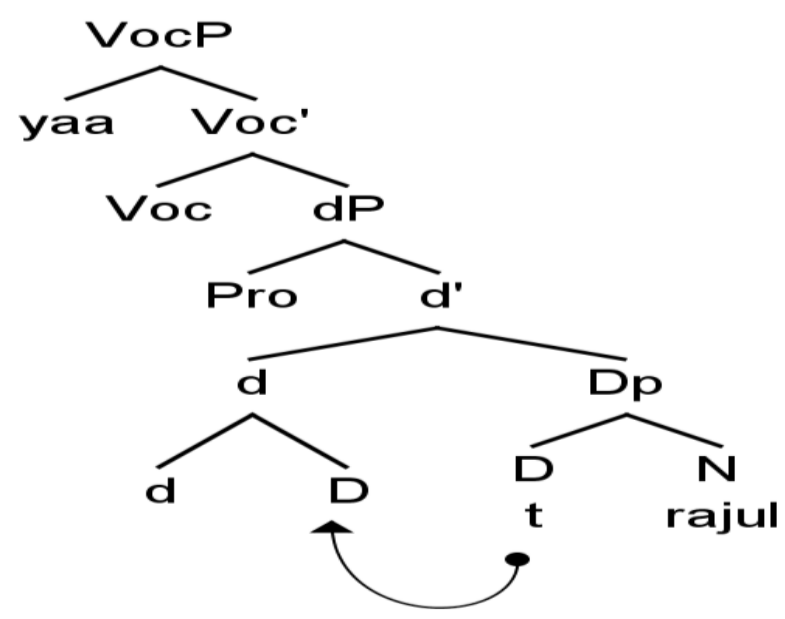

\subsection{Proper names}

The same analysis suggested for indefinite nouns may account for Case alternation of vocative proper names like the following:

38. a. yaa zayd-a-n

O Zayd-ACC-n

'Oh Zayd (among other Zayd's).'

b. yaa zayd-u

O Zayd-NOM

'Oh Zayd!'

(Fassi Fehri, 2012:195)

The proper name Zayd in (38a) is assigned the accusative Case in the same way that rajul in yaa rajul-a- $n$ discussed above receives accusative Case. That is to say, zayd is merged with the indefinite article $-\mathrm{n}$ which requires $\mathrm{N}$-to-D movement, the resulting DP zayd- $n$ raises to light $d$ and is assigned accusative Case. In (38b), zayd does not attach to the null D, so the D-to-d movement leaves zayd in situ. Being unable to move to light $\mathrm{d}$, zayd is assigned the nominative Case by default.

\subsection{Construct State}

Unlike indefinite nouns and proper names which can be either nominative or accusative, the Construct State is always accusative as in (12b), repeated as (39):

39. yaa Sadiiq-a camr-i-n, saacid Sadiiq-a-ka

$\mathrm{O}$ friend-ACC Amr-GEN-n help friend-ACC-2s (GEN)

'Friend of Amr, help your friend.'

The vocative noun Sadiiq 'friend' is assigned the accusative marker -a. At the first sight, the Construct State seems contradictory to the previous argument since the head of the Construct State Sadiiq does not (actually cannot) have an overt determiner (i.e, neither definite article al nor indefinite article $-n$ ). However, the existence of an overt determiner is not the only Case that triggers N-to-D movement since there are other causes for the movement. In the Case of Construct States, the movement is related to definiteness spread. According to Bardeas (2009), the majority of the researchers (Borer, 1998; Fassi Fehri, 1989; Mohammad, 1990; Ritter, 1991; Siloni, 1991, among others) argue for N-to-D movement in Construct States to account for the major properties of Construct States, mainly Case assignment to the genitive phrase, definiteness spread and the position of adjectives. The N-movement takes place in order 
to assign a [+def] value to D. Ritter (1991, cited in Bardeas (2009:40)) argues that "N inherits the definiteness value of the genitive DP, and by moving to D, assigns the same value to D and consequently to the whole Construct State". In a similar vein, Borer (1998) assumes that "definiteness is base generated on N, and when this N moves to D, D gets the same definiteness value". Bardeas (2009) states that in the majority of proposals, D (or an element or a feature in D, like Agr (cf. Siloni, 1991) or Poss (cf. Ritter 1987)) is considered to assign Case on the genitive phrase. Under these proposals, Bardeas (2009: 55) represents the Construct State DP in (40) as in (41):

40. bait al-walad

house the-boy

'the boy's house'

41.

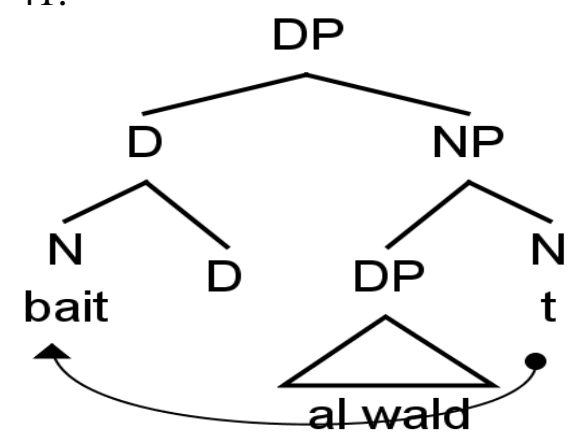

Agreeing with the previous researchers, I assume that in vocative phrases with Construct State, N-to-D movement takes place obligatorily (as in the case of indefinite nouns or proper names with affixal determiner $-n$ discussed above). Based on this assumption, the assignment of accusative Case to Sadiiq 'friend' in sentence (39), repeated as (42) can be straightforwardly analysed as follows:

42. yaa Sadiiq-a 'camr-i-n, saacid Sadiiq-a-ka

$\mathrm{O}$ friend-ACC Amr-GEN-n help friend-ACC-2s (GEN)

'Friend of Amr, help your friend.'

The noun Sadiiq starts in N with unvalued Case feature [uCase] and is merged with DP ${ }^{c} a m r-n$ (simplified by not showing its internal structure) to form NP. This NP is then merged with the null D (which is underspecified for definiteness) to form DP. N Sadiiq moves to $D$ to assign a [+def] value to it as follows:

43.

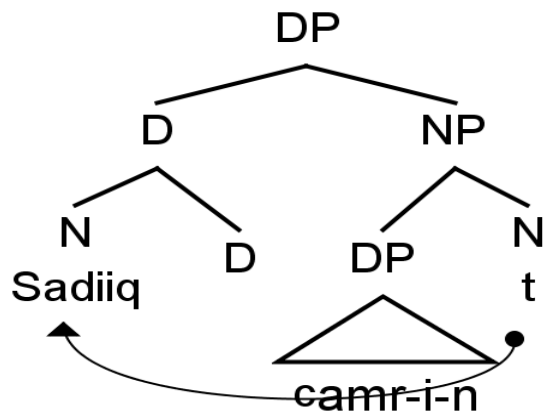

The N Sadiiq must move into D to get Case. According to Mohammad (1988:249), the importance of this movement is twofold: $\mathrm{N}$ reaches a position where it will be assigned Case (thus avoiding a violation of the Case Filter), and it will create the configuration under which the genitive Case is to be assigned to ${ }^{c} a m r-n$ to become ${ }^{c} a m r-i-n$. This DP is then merged with light $d$ with valued accusative feature to form 
d'. As stated by Larson (2014:413), light d "bears a strong D feature," so it is a strong affix (like little v) and attracts D Sadiiq. The transitive probe light $d$ assigns accusative Case to the goal D Sadiiq which it c-commands, consequently, Sadiiq becomes Sadiiq$a$. The resulting d-bar structure is then merged with pro since light $\mathrm{d}$ bears EPP feature to form the complex dP. Finally, the resulting $\mathrm{dP}$ is merged with voc to form voc' which is in turn merged with the particle yaa to form VocP as follows:

44.

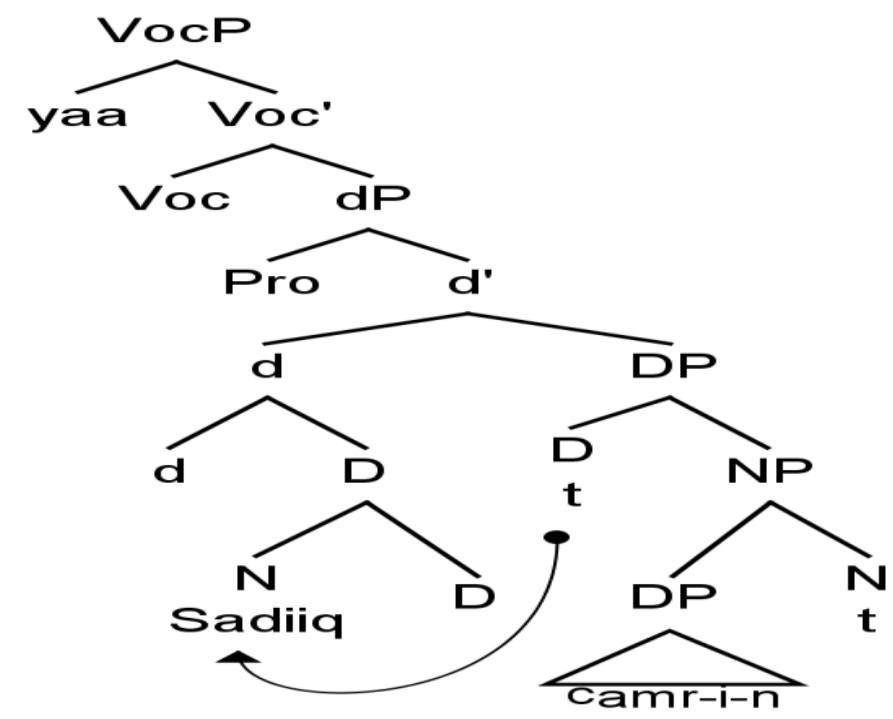

\subsection{Demonstratives}

Demonstratives in Arabic, namely, haaða "this" and ðaak "that," can be used prenominally and postnominally (as modifiers), and in both cases, the definite article al must be affixed onto the noun. According to Bardeas (2009: 44), Arabic demonstratives agree with the noun in gender, number and Case as in (45a-c) respectively:

45. a. haað-ihi al-fataat-u

this-f-s the-girl-NOM

b. haa?-olaa?i r-rijaal-u

these $(m-p)$ the-men-NOM

c. haað-aani al-kitab-aani

these (m-dual-NOM) the-books (m-d-NOM)

"these two books"

Two proposals are discussed in Bardeas (2009), namely, Kremers (2003) and Shlonsky (2004) which assume that prenominal demonstratives are heads of Dem(onstrative) projections. The difference between the two proposals is that Kremers projects "Dem" above "D", whereas Shlonsky projects "Dem" below "D" and assumes that Dem moves and adjoins to D. Unlike Shlonsky's proposal, Kremers's analysis explains the order Dem-D-N in a straightforward way and is supported by the data. Agreeing with Bardeas (2009), I assume that the prenominal demonstratives project above $\mathrm{D}$. Bearing in mind the previous properties of demonstratives, namely, agreement with the noun in (45a-c) and the projection above $\mathrm{D}$, we can account for the vocative phrase in (46): 
46. yaa haaða r-rajul-u, btacid qaliilan

$\mathrm{O}$ that the-man-NOM move away a little

'O that man, move away a little.

The noun rajul starts in $\mathrm{N}$ with unvalued Case feature [uCase] and is merged with $\mathrm{D} a l$ to form DP, and the noun rajul moves to al (realized as $r$-). The DP is then merged with Dem haaða to form DemP which is in turn merged with light $\mathrm{d}$ with valued accusative feature to form d'. At this stage of the derivation, the light $d$ is separated from $D$ by the functional head Dem, therefore, the D-to-d movement is prevented because of the blocking effect of the intervening functional head (cf. Deprez, 2003:140). To illustrate, Radford (2009:358) indicates that

a light verb cannot assign accusative Case to a nominal if there is an overt constituent intervening between the two (so that an intervening adverbial adjunct blocks accusative Case-marking, e.g. in structures such as *He closed immediately the door).

Considering the structural similarity between light $\mathrm{v}$ and light $\mathrm{d}$, it is safe to claim that Lexical D $r$-rajul must be merged as close to its Case assigner (i.e., light d) in order to be assigned accusative Case. In other words, I claim that D-to-d movement is subject to the following condition:

Adjacency condition: A condition requiring that two expressions must be immediately adjacent (i.e. there must be no constituent intervening between the two) in order for some operation to apply (Radford, 2009:439) ${ }^{1 .}$

Since the light $\mathrm{d}$ is not immediately adjacent to $\mathrm{D}$ r-rajul, the D-to-d movement does not take place, and both the Dem haaða and D r-rajul are assigned nominative Case by default. The derivation proceeds with the merger of d' with pro to form $\mathrm{dP}$ which is in turn merged with voc to form voc', and voc' is merged with the particle yaa to form VocP as follows:

47.

\footnotetext{
${ }^{1}$ Based on Abney (1987:284-285, cited in Panagiotidis, 2000: 718), one may argue that demonstratives are determiners since they "form a closed class, do not carry descriptive features and occur in complementary distribution with articles: *this the man." Consequently, the D-to-d movement is subject to another condition, namely, intervention condition: Probe P cannot target goal G if there is some other visible goal of the same kind as $\mathrm{G}$ intervening between the two and if the intervening goal is inactive for $P$ (Radford, 2009:419). However, Arabic demonstratives cannot be considered as determiners since they obligatorily co-occur with the definite article $a l$, as in the vocative phrase under discussion.
} 


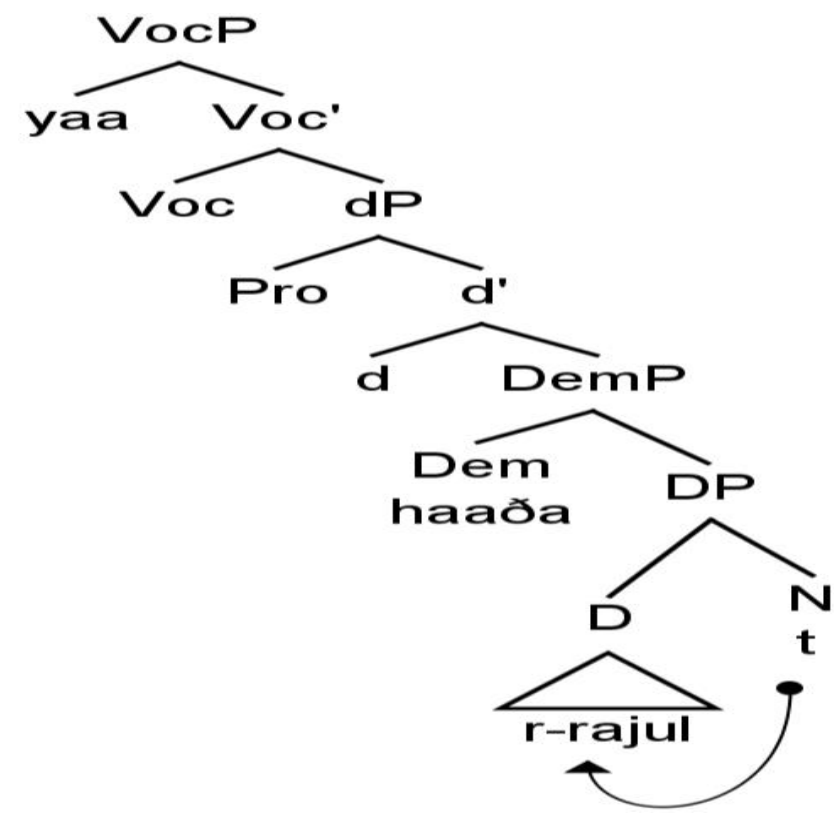

The argument of adjacency requirement can be rendered further support by considering vocative phrases with definite nouns as in the following:

48. Payyuha n-naaPim-u, stayqiD

$\mathrm{O}$ the-sleeping one-NOM wake up

As indicated by Moutaouakil (1989:152), the particle Payyuhaa is analysed by the majority of traditional grammarians to be composed of two parts, namely, the vocative particle ?ayyu and the demonstrative $h a$ which is an abbreviated form of haaða. This indication renders (48) above to have the same analysis as (46) except that the demonstrative $h a$ behaves like a clitic and moves higher in the structure to attach to the particle ?ayyu as in (49):

49.

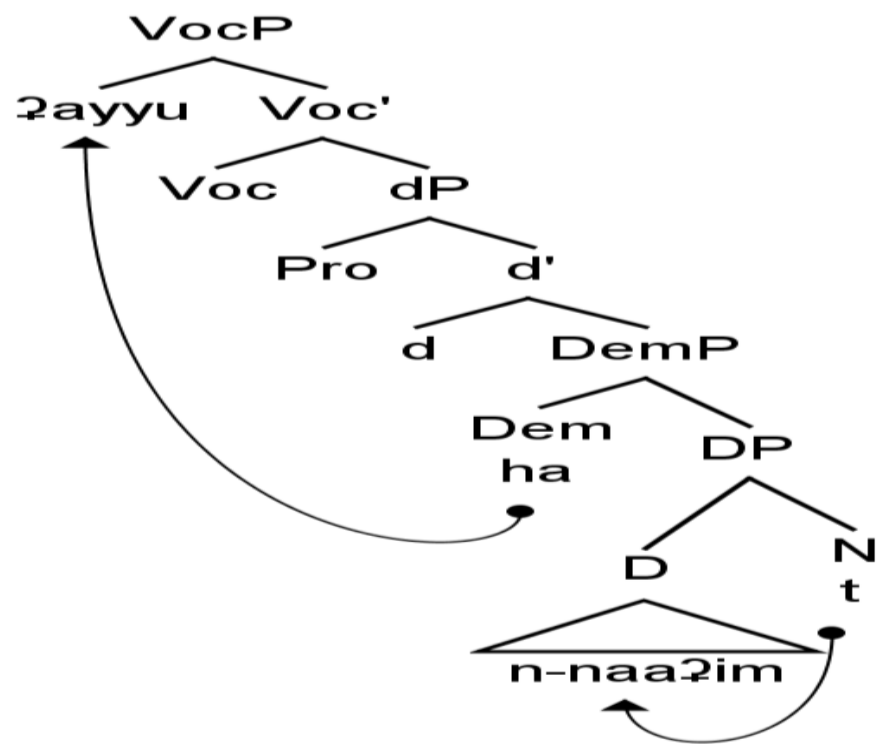

The light $\mathrm{d}$ cannot attract $\mathrm{D}$ n-naafim because of the intervening overt constituent Dem $h a$, so D is assigned the nominative Case by default and becomes $n$-naa?im- $u$. the Dem $h a$, being an abbreviated form of haaða, behaves like a clitic with an affixal nature (due to its reduced form, it cannot stand by itself and needs to be attached to an appropriate host). It moves higher in the structure to adjoin the particle ?ayyu with the result fayyuha is used as one particle. This assumption is based on the fact that unlike other particles like yaa, fayyuha occurs only with definite nouns (but not with indefinite 
nouns, proper names or Construct States). The unique behavior of 7ayyuha indicates that it is not a simple particle like $y a a$, rather it is a combination of a particle and a demonstrative which occupies a lower position in the structure at an early stage of the derivation. Assuming the structure of Payyuha as a simple particle makes us unable to account for its co-occurrence with definite nouns, or the impossibility of the cooccurrence of definite nouns with other particles. However, the analysis of zayyuha nnaatim- $u$ renders further support to our claim that the nominative Case on the noun is caused by the imperfect checking domain due to the intervening Dem.

\section{Conclusion}

This paper examines the syntactic structure of Arabic vocatives, focusing on Casemarking of vocatives. I argue that the semantic analysis of Case alternation seems inadequate and problematic, and a syntactic account within the minimalist approach may provide a better explanation of this linguistic phenomenon. Although vocative phrases occupy an external position within sentences, they have internal structure which is syntactically constrained. I argue that the different Case assignments of vocatives can be accounted for in the light of Hill (2017) and Larson (2014)'s proposals. Hill (2017) provides the basic structure for the vocative phrase, and Larson (2014) proposes the internal structure within the DP. The combination of these proposals provides the accurate derivation of Arabic vocatives and explains Case alternation.

In the foregoing discussion, I have shown that indefinite vocatives are assigned accusative Case only if they are merged with an overt D - $n$, otherwise a nominative Case surfaces on the noun by default. Proper names have the same analysis since the presence of the indefinite article-n is a prerequisite for accusative Case assignment. Concerning vocatives as heads of Construct States, N-to-D movement takes place in order to assign [+def] feature to $\mathrm{D}$ and is assigned accusative Case once $\mathrm{D}$ raises to the light $\mathrm{d}$. Regarding vocatives in demonstrative phrases, D-to-d movement is blocked because of the intervening constituent Dem, indicating that this operation is subject to the adjacency condition. The same analysis is applicable to definite vocatives occurring with the particle ?ayyuha.

\section{References}

Abney, S. P. (1987). The English noun phrase in its sentential aspect (Phd). MIT, Cambridge, MA.

Al-Balushi, R. A. (2011, April 26). Case in Standard Arabic: The Untraveled Paths (PhD Thesis). University of Toronto, Toronto.

Alkuwaihes, G. (2017). The Derivation of Vocative Exclamatives with the Particle Paya in Gulf Arabic. International Journal of Language and Linguistics, 5(5), 121. https://doi.org/10.11648/j.ijll.20170505.11

Bardeas, S. M. (2009). The Syntax of the Arabic DP (Ph.D.). The University of York.

Beina, M. C. (2013). The syntax of the Arabic determiner phrase (Masters). Eastern Michigan University, Michigan.

Borer, H. (1984). Parametric syntax, case studies in Semitic and Romance languages. Foris Publications. 
Borer, H. (1998). Deconstructing the construct. In K. Johnson \& I. Roberts (Eds.), Beyond Principles and Parameters: Essays in Memory of Osvaldo Jaeggli (pp. 43-89). Dordrecht: Springer Science \& Business Media.

Daniel, M., \& Spencer, A. (2009). The Vocative - An Outlier Case. In A. Malchukov \& A. Spencer (Eds.), The Oxford Handbook of Case (pp. 626-634). Oxford, New York: Oxford University Press.

Deprez, V. (2003). Haitian Creole Se: a Copular, a Pronoun, Both or Neither? On the Double Life of a Functional Head. In D. Adone (Ed.), Recent Development in Creole Studies (pp. 135-174). Walter de Gruyter.

Fassi Fehri, A. (1989). Generalised IP structure, case, and VS word order. In MIT Working Papers in Linguistics 10 (pp. 75-111).

Fassi Fehri, A. (1993). Issues in the Structure of Arabic Clauses and Words. Springer Netherlands.

Fassi Fehri, A. (2012). Key Features and Parameters in Arabic Grammar. Amsterdam, NETHERLANDS: John Benjamins Publishing Company.

Frege, G. (1950). The Foundations of Arithmetic. A logico-mathematical enquiry into the concept of number ... Translation by J. L. Austin. (Die Grundlagen der Arithmetik.) Ger. \& Eng. Oxford: Basil Blackwell.

Hill, V. (2007). Vocatives and the pragmatics-syntax interface. Lingua, 117(12), 20772105 .

Hill, V. (2017). Vocatives in the Balkans. Revista Letras, 96(0), 334-353.

Hill, V., \& Stavrou, M. (2014). Vocatives: How Syntax Meets with Pragmatics. Leiden, NETHERLANDS: BRILL.

Kasher, A. (2013). The Vocative as a "Speech Act" in Early Arabic Grammatical Tradition. Histoire Épistémologie Langage, 35(1), 143-159.

Kremers, J. M. (2003). The Arabic Noun Phrase: A Minimalist Approach (PhD). University of Nijmegen.

Lambrecht, K. (1996). On the Formal and Functional Relationship between Topics and Vocatives. In A. E. Goldberg (Ed.), Conceptual structure, discourse, and language (pp. 267-288). Stanford, Calif: CSLI Publications.

Larson, R. K. (2014). On Shell Structure (1 edition). New York and London: Routledge.

Levinson, S. C. (1983). Pragmatics. Cambridge: Cambridge University Press.

Mohammad, M. (1990). The problem of subject-verb agreement in Arabic: Toward a solution. In M. Eid (Ed.), Perspectives on Arabic Linguistics I: Papers from the First Annual Symposium on Arabic Linguistics (pp. 95-125). Amsterdam: John Benjamins Publishing.

Mohammad, M., A. (1988). On the Parralelism between IP and Dp. In H. Borer (Ed.), Proceedings of the 7th West Coast Conference on Formal Linguistics (pp. 241253). Center for the Study of Language (CSLI). 
Mohammad, M., A,. (2000). Word Order, Agreement, and Pronominalization in Standard and Palestinian Arabic. John Benjamins Publishing.

Moro, A. (2003). Notes on Vocative Case: A Case Study in Clause Structure. In J. Quer, J. Schroten, M. Scorretti, P. Sleeman, \& E. Verheugd (Eds.), Romance Languages and Linguistic Theory 2001: Selected Papers from "Going Romance," Amsterdam, 6-8 December 2001 (pp. 247-262). Amsterdam/Philadelphia: John Benjamins Publishing.

Moutaouakil, A. (1989). Pragmatic Functions in a Functional Grammar of Arabic (Reprint 2014). Berlin, Boston: De Gruyter Mouton.

Ouhalla, J. (1988). The syntax of head movement: a study of Berber (Doctoral). University of London.

Panagiotidis, P. (2000). Demonstrative determiners and operators: The case of Greek. Lingua, 110(10), 717-742.

Radford, A. (2009). Analysing English Sentences: A Minimalist Approach. Cambridge University Press.

Ritter, E. (1987). NSO noun phrases in Modern Hebrew. In J. McDonough \& B. Plunkett (Eds.), NELS : proceedings of the North East Linguistic Society 17 (pp. 521-537).

Ritter, E. (1991). Two functional categories in Noun Phrases: evidence from Modern Hebrew. In Syntax and Semantics: Perspectives on Phrase Structure: Heads and Licensing 25 (pp. 37-62). Academic Press.

Rubin, E. (2002). Romanian Nominals, Proforms, And Genitive Case Checking. In T. Satterfield, C. Tortora, \& D. Cresti (Eds.), Current Issues in Romance Languages: Selected Papers from the 29th Linguistic Symposium on Romance Languages (LSRL), Ann Arbor, 8-11 April 1999 (pp. 287-324). John Benjamins Publishing.

Shlonsky, U. (2004). The form of Semitic noun phrases. Lingua, 114(12), 1465-1526.

Siloni, T. (1991). Noun raising and the structure of noun phrases. In J. Bobaljik \& T. Bures (Eds.), Papers from the Third Student Conference in Linguistics (MITWPL vol 14) (pp. 255-270).

Slocum, P. (2016). The Syntax of Address (Ph.D.). State University of New York at Stony Brook, United States -- New York.

Soltan, U. (2007). On Formal Feature Licensing in Minimalism: Electronic Resource : Aspects of Standard Arabic Morphosyntax. University of Maryland.

Sonnenhauser, B., \& Hanna, P. N. A. (2013). Vocative!: Addressing between System and Performance. Walter de Gruyter.

Stavrou, M. (2014). About the Vocatives. In L. Schürcks, A. Giannakidou, \& U. Etxeberria (Eds.), The Nominal Structure in Slavic and Beyond (pp. 299-342). Mouton: Walter de Gruyter. 
Woolford, E. (2003). Nominative objects and case locality. In W. Browne (Ed.), Formal Approaches to Slavic Linguistics \#11: Amherst (pp. 539-568). Ann Arbor: Michigan Slavic Publications.

Zwicky, A. (1974). Hey, whatsyourname! In M. La Galy, R. Fox, \& A. Bruck (Eds.), Papers from the 10th Regional Meeting of the Chicago Linguistic Society (pp. 787-801). 